\title{
Obesity in British children with and without intellectual disability: cohort study
}

Eric Emerson ${ }^{1,2^{*}}$, Janet Robertson ${ }^{1}$, Susannah Baines ${ }^{1}$ and Chris Hatton ${ }^{1}$

\begin{abstract}
Background: Reducing the prevalence of and inequities in the distribution of child obesity will require developing interventions that are sensitive to the situation of 'high risk' groups of children. Children with intellectual disability appear to be one such group. We aimed to estimate the prevalence of obesity in children with and without intellectual disability in a longitudinal representative sample of British children and identify risk factors associated with obesity at age 11 .

Methods: Information was collected on a nationally representative sample of over 18,000 at ages 9 months, 3, 5, 7 and 11 years. We used UK 1990 gender-specific growth reference charts and the LMS Growth programme to identify age and gender-specific overweight and obesity BMI thresholds for each child at ages 5,7 and 11 years.

Results: Children with intellectual disabilities were significantly more likely than other children to be obese at ages five $(O R=1.32[1.03-1.68])$, seven $(O R=1.39[1.05-1.83])$ and eleven $(O R=1.68[1.39-2.03])$. At ages five and seven increased risk of obesity among children with intellectual disabilities was only apparent among boys. Among children with intellectual disability risk of obesity at age eleven was associated with persistent maternal obesity, maternal education, child ethnicity and being bullied at age five.

Conclusions: Children with intellectual disability are a high-risk group for the development of obesity, accounting for 5-6\% of all obese children. Interventions to reduce the prevalence and inequities in the distribution of child obesity will need to take account of the specific situation of this group of children.
\end{abstract}

\section{Background}

Reducing child obesity is a key public health priority internationally [1-3] and in many high income countries [4-7]. Reducing the prevalence and inequities in the distribution of child obesity will require developing interventions that are sensitive to the situation of 'high risk' groups of children [8]. Children with intellectual disability appear to be one such high risk group. Intellectual disability refers to a significant general impairment in intellectual functioning that is acquired during childhood [9]. Estimates of the prevalence of intellectual disability derived from epidemiological studies vary widely, with pooled estimates for children suggesting a point prevalence of $1.83 \%$ (95\% CI confidence intervals 1.52 $2.14 \%$ ) [10]. However, it has been estimated by Public

\footnotetext{
* Correspondence: eric.emerson@lancaster.ac.uk

${ }^{1}$ Centre for Disability Research, Lancaster University, Lancaster, UK

${ }^{2}$ Centre for Disability Research and Policy, University of Sydney, Sydney, New South Wales, Australia
}

Health England that approximately $3 \%$ of the child population of England have an intellectual disability [11].

The available evidence suggests that children with disabilities generally [12-14], and children with intellectual disability specifically, are at increased risk of overweight and/or obesity [15]. The increased risk of obesity among children with intellectual disability has been reported in a diverse range of countries including Australia [16, 17], France [18, 19], Japan [20], Korea [21], Taiwan [22], the UK [23-25] and the USA [26-28]. The only exception to this pattern being one report of lower rates of obesity among children with intellectual disabilities in Hong Kong [29].

Among children with intellectual disabilities higher rates of obesity have been reported among: older children [16-18, 20-22, 25, 26]; girls [18, 20, 21, 30]; boys [26]; children with Down syndrome [18]; children taking psychoactive medication [18]; children living in poorer families [16]; children living in more socially deprived 
neighbourhoods [16]; and children in high income countries [30, 31]. However, only the association between obesity and age has been reported with any degree of consistency [15]. Among adults with intellectual disabilities higher rates of obesity have been reported among women, people with Down's syndrome, people with less severe intellectual disabilities, people living in less restrictive residential environments and people living in more socially deprived neighbourhoods [32-34].

The existing literature does, however, have two significant limitations. First, the majority of studies have relied on convenience samples (e.g., children attending special schools [18, 20,21, 24, 25, 28, 29], children participating in Special Olympics $[26,30,31,35])$ that are unlikely to be representative of the wider population of children with intellectual disabilities. Second, the vast majority of studies have employed cross-sectional designs. The aims of the present paper are to redress these deficiencies in the existing evidence-base by: (1) estimating the prevalence of overweight and obesity across early and middle childhood in children with and without intellectual disability in a longitudinal representative sample of British children; (2) identify risk factors associated with overweight and obesity in children with intellectual disability at age 11 .

\section{Method}

The UK's Millennium Cohort Study (MCS) is the fourth in the series of British birth cohort studies. It aims to follow throughout their lives a cohort of over 18,000 children born in the UK between 2000 and 2002. MCS data are managed by the Centre for Longitudinal Studies at the University of London (www.cls.ioe.ac.uk/) and are available to researchers registered with the UK Data Service (www.ukdataservice.ac.uk) (www.esds.ac.uk). Full details of the design of MCS are available in a series of reports and technical papers [36-42] key aspects of which are summarised below.

\section{Sampling}

Participant families were randomly selected from Child Benefit Records, a non means-tested welfare benefit available to all UK children at the time the cohort was established. Sampling was geographically clustered to include all four countries of the UK (England, Wales, Scotland, Northern Ireland), and disproportionately stratified to over-sample children from ethnic minority groups and disadvantaged communities [43]. Children and families were drawn from 398 randomly selected electoral wards in the UK. The first survey (MCS1) took place when children were nine months old and included a total of 18,552 families. Children were followed up at ages three (MCS2; 15,590 families, $78 \%$ response rate), five (MCS3; 15,246 families, $79 \%$ response rate), seven
(MCS4; 13,857 families, response rate) and eleven (MCS5; 13,287 families, 69 \% response rate). For each family, information was collected on the target child falling within the designated birth date window. For multiple births (e.g., twins, triplets) information was collected on all children. To avoid the statistical problems associated with the clustering of multiple births within households, the present analyses are restricted to the first named target child in multiple birth households. All analyses used sampling weights provided with MCS data to adjust for the initial sampling design and biases in recruitment and retention at specific ages.

\section{Identification of children with intellectual disability}

Child cognitive ability was assessed at age three using the Bracken School Readiness Assessment [44] and Naming Subscale of the British Ability Scales (BAS) [45], selected subscales of the BAS at ages five and seven, and the NFER Progress in Maths test at age seven [46]. At age 11 children were given three cognitive tests; verbal similarities (BAS), the Spatial Working Memory task and the Cambridge Gambling task, both from the Cambridge Neuropsychological Test Automated Battery. Of the age eleven tests, only verbal similarities is closely related to traditional measures of IQ.

For ages five and seven we extracted the first component (' $\mathrm{g}$ ') from a principal component analysis of all agestandardised subscale/test scores [47]. The first component accounted for $63 \%$ of score variance at age seven and $55 \%$ of score variance at age five. We identified children as having intellectual disability if they scored two or more standard deviations below the mean on the first principal component at age seven $(n=419$ [3.3\%] of 12,820 children for whom test results were available).

If cognitive test scores were missing at age seven, we identified children as having intellectual disability if they scored two or more standard deviations below the mean on the first principal component at age five $(n=146$ [6.5\%] of 2,250 children). If cognitive test scores were missing at age five and at age seven, we identified children as having intellectual disability if they scored two or more standard deviations below the mean on the Bracken School Readiness Assessment at age three $(n=$ 49 [4.4\%] of 1105 children). If Bracken scores were not available, we identified children as having intellectual disability if they scored two or more standard deviations below the mean on the BAS Naming Subscale at age three $(n=54$ [7.6 \%] of 711 children). This process allowed us to classify intellectual disability on the basis of cognitive test scores for $99.1 \%$ of children participating at age seven.

For 125 children no cognitive test results were available at any age. Interviewers did not administer the assessments if the child 'has a learning disability/serious 
behavioural problem (e.g., severe ADHD, autism) which prevents them from carrying out the assessments', 'is unable to respond in the required manner for each assessment, e.g., reading, writing, manipulating objects', 'is not able to speak or understand English (or Welsh if applicable)' or if consent and co-operation were not forthcoming. For these children we identified intellectual disability on the basis of parental report at age seven. A child was identified as having learning disabilities if both of the following two criteria were met: (1) the child was reported to be receiving special education due to their 'learning difficulty' (the term used in educational services in the UK to refer to intellectual disability); (2) the child was reported to have 'great difficulty' in all three areas of reading, writing and maths. This led to the identification of another 11 children as having intellectual disability ( $8.8 \%$ of children for who no test scores were available).

Finally, we used the normalised verbal similarities standard score at age eleven to attempt to address potential errors in classification in the W2-4 variables. Specifically, all children who had been identified as having intellectual disability who scored at or above the population mean on verbal similarities at age eleven were reclassified as not having intellectual disability. Similarly, all children identified as not having intellectual disability but who scored three or more standard deviations below the population mean on verbal similarities at age eleven were reclassified as having intellectual disability.

This procedure led to the identification of 647 of the 18,495 (3.5 \%) children participating at Wave 1 where the child's mother was the primary informant as having intellectual disability. As expected, boys were significantly more likely than girls to be identified as having intellectual disability ( $4.3 \%$ vs $2.6 \%$; OR $=1.67,95 \% \mathrm{CI}$ 1.42-1.96).

\section{Overweight \& obesity}

Measurements of child height and weight were taken and BMI calculated at ages three (MCS2), five (MCS3), seven (MCS4) and eleven (MCS5). MCS data releases include categorical measures of overweight and obesity based on the International Task Force childhood obesity reference charts and cut-off points [48]. At ages three and five, $5 \%$ of cohort members were identified as obese $[49,50]$. However, studies have suggested that: (1) the international reference lacks specificity due to the sample size used to define the population; (2) their use may lead to the under-reporting of rates of obesity; and (3) international reference charts may ignore population differences in the relationship between BMI and adiposity [51]. As a result, more recent studies of child obesity using MCS data have used UK-specific growth reference charts to recalculate overweight and obesity from BMI, age and gender data [52].
In the present study we used UK 1990 gender-specific growth reference charts and the LMS Growth programme to identify age and gender-specific overweight and obesity BMI thresholds for each child at ages 5,7 and 11 years [53, 54]. The use of UK 1990 BMI growth reference charts to calculate obesity is not recommended under 4 years of age [55]. Children whose BMI fell at or above the 85th percentile of the UK 1990 reference population were defined as overweight, and those at or above the 95th percentile were defined as obese $[55,56]$.

\section{Predictor variables}

Previous research undertaken with the MCS has reported that increased risk of overweight and obesity was associated with a range of variables including ethnicity, higher birth weight, early introduction of solid foods, missing breakfast, sedentary lifestyle, maternal smoking (including during pregnancy), parental overweight (including pre-pregnancy overweight), lone motherhood, maternal employment, low parental educational attainment, low income, material hardship, living in more socially deprived neighbourhoods $[23,49,50,52]$. The following potential predictor variables were extracted from MCS data collected in Waves 1-4.

\section{Child ethnicity}

Child ethnicity was based on parental report and coded using the six category UK Census scheme: White; Mixed Ethnicity; Indian; Pakistani or Bangladeshi; Black or Black British; Other.

\section{Child birth weight}

Parental report of child birth weight was collected at Wave 1 . These data were recoded into a binary measure of higher birth weight based on falling within the upper quartile of the weighted sample distribution $(>3.70 \mathrm{~kg})$.

\section{Child nutrition}

At Wave 1 (9 months) information was collected from the main parental informant on the age at which the child first had solid foods. These data were recoded into a binary measure of introduction of solid foods in the first three months of life [52].

At Waves 3 and 4 information was collected from the main parental informant on: (1) the number or portions of fruit eaten daily; (2) the main type of between-meal snacks the child eats; and (3) the number of days the child has breakfast. Following inspection of the distribution of these data, binary measures were derived of: (1) low levels of fruit consumption (less than two portions per day); (2) higher calorie snacks (the main type of snack being crisps, cakes or biscuits, sweets); (3) child skips breakfast one or more days per week. 


\section{Child participation in sport \& physical activity}

Parental report of child participation in sport was collected at Waves 3 and 4. Following inspection of the distribution of these data, binary measures of low levels of participation were derived based on participation on less than one day per week (age 5, Wave 3) and participation on less than two days per week (age 7, Wave 4). Parental report of child participation in physical activity sport was collected at Wave 4. Following inspection of the distribution of these data, a binary measure of low participation was derived based on participation on less than five days per week.

\section{Child tv watching and playing computer games}

Parental report of the time the child spends watching TV was collected at Waves 2-4. Parental report of the time the child spends playing computer games was collected at Waves 3 and 4. Binary measures of high levels of TV watching or computer game playing were derived based on watching/playing for three or more hours daily. At Wave 4 information was also collected on whether the child had a TV in their bedroom.

\section{Child exposure to bullying}

The Strengths and Difficulties Questionnaire [57] was completed by parents at Waves 2-4. One item 'Picked on or bullied by other children' was used to identify exposure to bullying at ages three, five and seven.

\section{Maternal obesity}

Maternal BMI was calculated from self-reported height and weight at each of the four MCS waves and retrospectively at Wave 1 for pre-pregnancy weight. Obesity was defined as a BMI of 30 or more. Maternal obesity status over time was coded as never, once or twice, three or more times.

\section{Maternal smoking}

Information was collected at each Wave on whether the child's mother was a current smoker. Following inspection of the distribution of these data a binary measure of maternal smoking was derived based on being a current smoker at two or more of the four waves of data collection.

\section{Maternal educational attainment}

Highest level of educational attainment across waves was coded according to National Vocational Qualifications (NVQ) categories.

- No qualifications or NVQ Level 1: Competence that involves the application of knowledge in the performance of a range of varied work activities, most of which are routine and predictable (equivalent to one General Certificate of Secondary Education (GCSE) at grade D-G).
- NVQ Level 2: Competence that involves the application of knowledge in a significant range of varied work activities, performed in a variety of contexts. Collaboration with others, perhaps through membership of a work group or team, is often a requirement (equivalent to one GCSE at grade $\mathrm{A}^{*}$-C).

- NVQ Levels 3-5: NVQ Level 3 requires competence that involves the application of knowledge in a broad range of varied work activities performed in a wide variety of contexts, most of which are complex and non-routine. There is considerable responsibility and autonomy and control or guidance of others is often required (equivalent to 1-5 Advance Level certificates at grades $\mathrm{A}^{*}-\mathrm{C}$ ).

- Overseas qualifications only.

\section{Maternal employment}

Information on maternal employment and hours worked was collected at each Wave. High levels of hours worked were defined at each wave as working for more than $20 \mathrm{~h}$ per week [52].

\section{Single parent family}

Information on household composition was collected at each Wave. Following inspection of the distribution of these data a single binary measure of single parent family was derived based on being a single parent family at any of the four waves of data collection.

\section{Household income poverty}

Information on household income was collected at each Wave. These were adjusted for household composition using the modified OECD equivalisation scale [58] and used to define household income poverty (equivalised household income falling $60 \%$ below the population median) [59]. Following inspection of the distribution of these data a single binary measure of household income poverty was derived based on a household being in income poverty at any of the four waves of data collection.

\section{Area deprivation}

At each wave postcode data were linked to countryspecific area-based measures of multiple deprivation [60]. These were recoded into a binary measure of living in an area characterised by high levels of local area deprivation based on living in an area in the lowest quintile of neighbourhoods in a given country at all four waves of data collection (vs. not).

\section{Approach to analysis}

In the first stage of analysis we used simple bivariate descriptive statistics to estimate the prevalence of overweight and obesity at ages five, seven and eleven for children with and without intellectual disability. In the 
second stage of analysis we used simple bivariate descriptive statistics to estimate the persistence of obesity between successive waves of data collection for children with and without intellectual disability.

In the third stage of analysis we examined bivariate associations between the predictor variables listed above and obesity at age 11 in the full sample. Missing data on predictor variables was imputed using multiple imputation routines in SPSS 20 to create five parallel data sets. The results of pooled analyses were used to exclude predictor variables from subsequent analyses if they had no statistically significant association with child obesity. This led to the exclusion of all measures of maternal employment and at Wave 4 indicators of having a TV in the child's bedroom, the number of days of physical activity and the main type of between-meal snack. In the fourth stage of analysis we determined the strength and statistical significance of the bivariate association between remaining predictor variables and child obesity at age 11 for children with and without intellectual disability.

In the fifth stage of analysis we used multivariate logistic regression to determine the unique strength and statistical significance of the association between predictor variables that were either significantly associated or showed moderate or greater effect sizes in relation to obesity at age 11 among children with intellectual disability. In the final stage of the analysis we applied the model from the fifth stage to the sub-sample of children without intellectual disability. The aim of this stage of the analysis was to investigate whether there were any marked difference in the strength of association between predictor variables and obesity that were significant for children with intellectual disability when applied to children without intellectual disability. We did not undertake any further analyses of the non-intellectual disability subsample as data has been reported elsewhere on the full sample, the results of which are driven by the non-intellectual disability subsample $[49,50,52]$. In the final two stages of the analyses missing data on predictor variables was imputed using multiple imputation routines in SPSS 20 to create five parallel data sets. The results of pooled analyses were reported.

All analyses used appropriate wave-specific weights to take account of biases in the sampling frame (e.g., oversampling of households in Scotland, Wales and Northern Ireland), initial recruitment and attrition over time.

\section{Results}

\section{The prevalence of child obesity}

Mean BMI, height and weight by age, intellectual disability status and gender are presented in Table 1 . Table 2 presents estimated prevalence rates for overweight and obesity at ages 5, 7 and 11 years for boys and girls with
Table $1 \mathrm{BMI}$, height and weight (mean, standard deviation and sample size) by age, intellectual disability status and gender

\begin{tabular}{llllll}
\hline Age & ID & & & No ID & \\
\cline { 2 - 3 } \cline { 6 - 6 } \cline { 5 - 6 } 5oys & years & Girls & & Boys & Girls \\
Height $(\mathrm{cm})$ & $109.6(5.6)$ & $107.8(5.8)$ & & $111.2(5.0)$ & $110.3(4.9)$ \\
Weight $(\mathrm{kg})$ & $20.1(4.1)$ & $19.1(3.0)$ & & $20.4(3.3)$ & $19.9(3.1)$ \\
BMl & $15.3(5.2)$ & $15.6(4.2)$ & & $16.1(2.8)$ & $16.1(2.6)$ \\
7 years & $N=282$ & $N=174$ & & $N=6380$ & $N=6217$ \\
Height $(\mathrm{cm})$ & $121.4(5.5)$ & $120.6(6.7)$ & & $124.2(5.6)$ & $123.3(5.5)$ \\
Weight $(\mathrm{kg})$ & $25.0(5.3)$ & $25.2(6.2)$ & & $25.7(4.9)$ & $25.4(4.9)$ \\
BMl & $16.9(2.8)$ & $17.1(3.1)$ & & $16.6(2.3)$ & $16.6(2.4)$ \\
11 years & $N=319$ & $N=204$ & & $N=7476$ & $N=7009$ \\
Height $(\mathrm{cm})$ & $144.1(8.3)$ & $143.7(8.5)$ & & $146.0(7.0)$ & $146.8(7.5)$ \\
Weight $(\mathrm{kg})$ & $41.2(11.7)$ & $42.6(11.0)$ & & $40.8(9.8)$ & $42.1(10.2)$ \\
BMl & $19.7(4.4)$ & $19.4(4.4)$ & & $19.0(3.5)$ & $19.4(3.7)$ \\
\hline
\end{tabular}

and without intellectual disability. Boys with intellectual disability were at significantly increased risk of obesity, when compared to boys without intellectual disability, at all ages. Girls with intellectual disability were at significantly increased risk of obesity, when compared to girls without intellectual disability at age 11 . They were also at significantly increased risk of overweight at age 7 . Overall, children with intellectual disability were not at significantly greater risk of overweight at any age. They were, however, at significantly greater risk of obesity at ages 7 and 11. At age 11, $5 \%$ of all obese children were children with intellectual disability.

\section{The persistence of child obesity}

Table 3 presents estimated persistence rates for obesity between ages 5, 7 and 11 years for children with and without intellectual disability. Column three presents estimates of the prevalence of persistent obesity (obese at time 1 and at time 2) within each of the two samples. Between ages five and seven and seven and eleven there were no statistically significant differences in the estimated prevalence of persistent obesity between children with and without intellectual disability. Between the ages of five and eleven, persistent obesity was marginally higher among children with intellectual disability $(\mathrm{z}=$ $2.32, p<0.05$ ).

Column four presents estimates of the relative risk of a child being obese at time 2 (e.g., 7 years old) if they were obese at time 1 (e.g., 5 years old). The comparison in the calculation of relative risk in these instances is the probability of a child from the same group being obese at time 2 if they were not obese at time 1 . In all instances and for each group, obesity at a later age was significantly and markedly greater (3-11 times more 
Table 2 Estimated prevalence of overweight and obesity at ages 5, 7 and 11 for boys and girls with and without intellectual disability

\begin{tabular}{|c|c|c|c|c|c|c|c|c|c|c|c|c|}
\hline & \multicolumn{4}{|c|}{ Overweight } & \multicolumn{4}{|l|}{ Obese } & \multicolumn{4}{|c|}{ Overweight or Obese } \\
\hline & ID & Not ID & $\begin{array}{l}\text { OR } \\
\text { (with } 95 \% \text { Cl)/p }\end{array}$ & $\%$ with ID & ID & Not ID & $\begin{array}{l}\text { OR } \\
\text { (with } 95 \% \text { Cl)/p }\end{array}$ & $\%$ with ID & ID & Not ID & $\begin{array}{l}\text { OR } \\
\text { (with } 95 \% \text { Cl)/p }\end{array}$ & $\%$ with ID \\
\hline \multicolumn{13}{|l|}{ Age 5} \\
\hline Boys & $13.5 \%$ & $15.7 \%$ & $0.82(0.59-1.13)$ & $3.6 \%$ & $17.2 \%$ & $12.8 \%$ & $1.41 *(1.05-1.89)$ & $5.7 \%$ & $30.2 \%$ & $28.6 \%$ & $1.08(0.85-1.38)$ & $4.5 \%$ \\
\hline Girls & $16.8 \%$ & $13.0 \%$ & $1.35(0.93-1.97)$ & $3.5 \%$ & $11.8 \%$ & $11.0 \%$ & $1.08(0.70-1.67)$ & $3.0 \%$ & $28.6 \%$ & $24.0 \%$ & $1.27(0.93-1.72)$ & $3.3 \%$ \\
\hline Total & $14.6 \%$ & $14.6 \%$ & $1.02(0.80-1.30)$ & $3.6 \%$ & $15.1 \%$ & $11.9 \%$ & $1.32 *(1.03-1.68)$ & $4.5 \%$ & $29.5 \%$ & $26.3 \%$ & $1.17(0.97-1.42)$ & $4.0 \%$ \\
\hline \multicolumn{13}{|l|}{ Age 7} \\
\hline Boys & $10.2 \%$ & $12.2 \%$ & $0.82(0.52-1.28)$ & $2.9 \%$ & $21.4 \%$ & $14.3 \%$ & $1.64^{* *}(1.17-2.28)$ & $5.0 \%$ & $31.6 \%$ & $26.5 \%$ & $1.29(0.96-1.72)$ & $4.1 \%$ \\
\hline Girls & $20.8 \%$ & $11.4 \%$ & $\mathbf{2 . 0 4} * *(0.35-3.07)$ & $4.2 \%$ & $11.8 \%$ & $12.3 \%$ & $0.95(0.57-1.59)$ & $2.3 \%$ & $32.6 \%$ & $23.8 \%$ & $1.55^{*}(1.09-2.21)$ & $3.2 \%$ \\
\hline Total & $14.5 \%$ & $11.8 \%$ & $1.26(0.94-1.70)$ & $3.5 \%$ & $17.5 \%$ & $13.3 \%$ & $1.39 *(1.05-1.83)$ & $3.8 \%$ & $32.0 \%$ & $25.1 \%$ & $1.40^{* *}(1.12-1.76)$ & $3.7 \%$ \\
\hline \multicolumn{13}{|c|}{ Age 11} \\
\hline Boys & $10.7 \%$ & $15.2 \%$ & $0.67^{*}(0.47-0.96)$ & $2.9 \%$ & $31.0 \%$ & $22.0 \%$ & $1.59 * * *(1.25-2.03)$ & $5.7 \%$ & $41.8 \%$ & $37.2 \%$ & $1.21(0.97-1.52)$ & $4.6 \%$ \\
\hline Girls & $17.2 \%$ & $13.9 \%$ & $1.28(0.89-1.85)$ & $3.4 \%$ & $31.2 \%$ & $20.2 \%$ & $1.79^{* * *}(1.33-2.42)$ & $4.3 \%$ & $48.3 \%$ & $34.1 \%$ & $1.80^{* * *}(1.36-2.38)$ & $3.9 \%$ \\
\hline Total & $13.2 \%$ & $14.6 \%$ & $0.89(0.69-1.16)$ & $3.2 \%$ & $31.1 \%$ & $21.2 \%$ & $1.68^{* * *}(1.39-2.03)$ & $5.0 \%$ & $44.4 \%$ & $35.7 \%$ & $1.44^{* * *}(1.20-1.71)$ & $4.3 \%$ \\
\hline
\end{tabular}

ORs in bold indicate medium or large effect size

$I D$ intellectual disability, $O R$ odds ratio, $p$ probability, $C l$ confidence interval

${ }^{*} p<0.05,{ }^{* *} p<0.01,{ }^{* * *} p<0.001$

likely) among children who were already obese. At all ages, there was a significantly stronger association between obesity at times 1 and 2 for children without intellectual disability.

\section{Predictors of child obesity}

As can be seen in Table 2, among children with intellectual disability rates of obesity were higher among boys than girls at age five $(\mathrm{OR}=1.55[0.93-2.58])$ and seven $(\mathrm{OR}=2.03[1.11-3.72])$. Similar, but weaker, associations were also seen among children without intellectual disability (age five $\mathrm{OR}=1.19$ [1.08-1.32], age seven $\mathrm{OR}=$ 1.18 [1.06-1.31]). By age eleven, however, the association between male gender and obesity was no longer apparent among children with intellectual disability $(\mathrm{OR}=0.99$

Table 3 The persistence of obesity in British children with and without intellectual disability

\begin{tabular}{|c|c|c|c|}
\hline Time period & Group & $\begin{array}{l}\text { Overall prevalence } \\
\text { (with 95\% Cl) of } \\
\text { persistent obesity } \\
\text { (obese at time } 1 \text { and } \\
\text { time 2) }\end{array}$ & $\begin{array}{l}\text { Relative risk } \\
\text { (with } 95 \% \mathrm{Cl} \text { and } \mathrm{p} \text { ) } \\
\text { of obesity at time } 2 \text { if } \\
\text { obese at time } 1\end{array}$ \\
\hline \multirow[t]{2}{*}{ Age 5 to 7} & ID & $7.6 \%(4.8-10.4 \%)$ & $5.69 * * *(3.99-8.91)$ \\
\hline & Not ID & $8.3 \%(7.8-8.8 \%)$ & $13.01^{* * *}(11.92-14.20)$ \\
\hline \multirow[t]{2}{*}{ Age 5 to 11} & ID & $11.2 \%(8.3-14.1 \%)$ & $3.11 * * *(2.45-3.95)$ \\
\hline & Not ID & $8.2 \%(7.7-8.6 \%)$ & $4.94^{* * *}(4.68-5.21)$ \\
\hline \multirow[t]{2}{*}{ Age 7 to 11} & ID & $11.6 \%$ (8.1-15.1\%) & $3.06 * * *(2.34-4.00)$ \\
\hline & Not ID & $10.6 \%$ (10.0-11.1\%) & $7.28^{* * *}(6.88-7.71)$ \\
\hline
\end{tabular}

Relative risks in bold indicate medium or large effect size $I D$ intellectual disability, $p$ probability, $\mathrm{Cl}$ confidence interval *** $p<0.001$
[0.68-1.45]), but did persist among children without intellectual disability (OR = $1.11[1.03-1.21])$.

Table 4 presents information on the strength and statistical significance of the bivariate association between predictor variables and child obesity at age 11 for children with and without intellectual disability. As described above, predictors were only included if there was a statistically significant association between the predictor and obesity at age 11 in the full (combined) sample. Given that children without intellectual disability made up $96.5 \%$ of the full sample, it is unsurprising that there were statistically significant associations between all predictors and obesity at age 11 among children without intellectual disability. Statistically significant associations between predictor variables and child obesity at age 11 were much rarer among children with intellectual disability, only being evident for maternal obesity, maternal educational attainment (overseas qualifications), child ethnicity (Black/Black British) and (somewhat paradoxically) high levels of fruit consumption at age five. The latter result should be treated with some caution as: (1) the association was no longer statistically significant in the subsequent multivariate analyses (Table 4); (2) the effect size is small;[61] and (3) opposite (though non-significant) associations between fruit consumption and obesity were evident at age seven. While not statistically significant moderate effect sizes were apparent for the association between being bullied at ages three and five and obesity at age eleven.

Given the marked differences in sample sizes (and hence statistical power) between the subsamples of children with and without intellectual disability, between 
Table 4 Bivariate associations between predictor variables (age 9 months to 7 years) and obesity in British children with and without intellectual disability at age 11

\begin{tabular}{lll}
\hline & Intellectual & No intellectual \\
& disability & disability \\
& $($ OR (with 95 \% Cl)/p) & $($ OR (with 95 \% Cl)/p) \\
\hline
\end{tabular}

Child Ethnicity

White
Mixed
Indian
Pakistani/Bangladeshi
Black/Black British
Other

Child Birth Weight (high)

Child Nutrition

Early introduction of solids

Low fruit consumption

(age 5)

Low fruit consumption

(age 7)

High caloriebetween-

meal snacks (age 5)

Does not eat breakfast every day (age 5)

Does not eat breakfast every day (age 7)

Child Participation in Sport

Low participation (age 5)

Low participation (age 7)

TV Watching \& Playing

Computer Games

High participation

(age 3, TV only)

High participation (age 5,

TV or computer games)

High participation (age 7,

TV or computer games)

Exposure to Being Bullied

Age 3

Age 7

Maternal Obesity

No occasion

Three to five occasions

Maternal Smoking

Maternal Educational

Attainment

NVQ (L3-5)
NVQ (L2)
NVQ (L1 or none)

$\begin{array}{ll}1 \text { (ref) } & 1 \text { (ref) } \\ \mathbf{2 . 7 4}(\mathbf{0 . 9 6 - 7 . 8 5}) & 1.43^{* *}(1.46-1.77) \\ 0.98(0.15-6.70) & 1.25(0.94-1.68) \\ 1.67(0.98-2.84) & 1.58^{* * *}(1.31-2.38) \\ \mathbf{2 . 5 1 * ( 1 . 1 7 - 5 . 3 6 )} & \mathbf{1 . 9 5 * *}(\mathbf{1 . 6 0 - 2 . 3 8}) \\ \mathrm{n} / \mathrm{a} & 0.92(0.647-1.32) \\ 0.67(0.9-1.16) & 1.21^{* * *}(1.11-1.33) \\ & \\ 1.35(0.85-2.14) & 1.38^{* * *}(1.24-1.52) \\ 0.57^{*}(0.33-0.98) & 1.26^{* * *}(1.13-1.40) \\ 1.29(0.75-2.24) & 1.24^{* *}(1.10-1.40) \\ 0.84(0.53-1.33) & 1.20^{* *}(1.06-1.36) \\ 1.13(0.64-1.98) & 1.82^{* * *}(1.51-2.20) \\ 1.80(0.98-3.31) & 1.52^{* * *}(1.26-1.82)\end{array}$

$0.83(0.54-1.29) \quad 1.39^{* * *}(1.28-1.52)$

$0.95(0.57-1.60) \quad 1.32 * * *(1.17-1.49)$

$0.95(0.60-1.51) \quad 1.22^{* *}(1.09-1.37)$

$1.02(0.65-1.61) \quad 1.38^{* * *}(1.24-1.54)$

$1.32(0.82-2.12) \quad 1.30^{* * *}(1.16-1.45)$

$1.91\left(\mathbf{0 . 8 0 - 4 . 5 3 )} \quad 1.52^{*}(1.07-2.15)\right.$

2.38 (0.95-5.96) $1.31(0.90-1.91)$

$1.50(0.49-4.57) \quad 1.77^{* * *}(1.40-2.24)$

1 (ref) 1 (ref)

$1.53(0.92-2.53) \quad \mathbf{2 . 7 4} \mathbf{4}^{* * *}(\mathbf{2 . 4 4 - 3 . 0 7 )}$

$5.48^{* * *}(3.03-9.93) \quad 3.76^{* * *}(3.33-4.25)$

$0.88(0.60-1.29) \quad 1.32 * * *(1.21-1.43)$

$\begin{array}{ll}1 \text { (ref) } & 1 \text { (ref) } \\ 1.52(0.81-2.86) & 1.55^{* * *}(1.40-1.72) \\ 1.16(0.65-2.10) & 1.75^{* * *}(1.57-1.94)\end{array}$

Table 4 Bivariate associations between predictor variables (age 9 months to 7 years) and obesity in British children with and without intellectual disability at age 11 (Continued)

\begin{tabular}{lll}
\hline $\begin{array}{l}\text { Overseas qualifications } \\
\text { only }\end{array}$ & $\mathbf{3 . 9 5}^{* *} \mathbf{( 1 . 4 9 - 1 0 . 5 0 )}$ & $1.41^{* *}(1.11-1.79)$ \\
$\begin{array}{l}\text { Single Parent Family } \\
\text { Household Income }\end{array}$ & $1.26(0.86-1.84)$ & $1.28^{* * *}(1.18-1.40)$ \\
$\begin{array}{l}\text { Poverty } \\
\text { High Area Deprivation }\end{array}$ & $1.47(0.75-2.89)$ & $1.41^{* * *}(1.28-1.54)$ \\
\hline
\end{tabular}

ORs in bold indicate medium or large effect size

$O R$ odds ratio, $p$ probability

${ }^{*} p<0.05,{ }^{* *} p<0.01,{ }^{* * *} p<0.001$

group comparisons should be made on estimates of the effect size (odds ratios) of associations rather than their statistical significance. While there was a stronger association between predictor variables and obesity among children without intellectual disability for $17(61 \%)$ of the 28 comparisons, this difference is not itself statistically significant (sign test $p=0.34$, n.s.).

Table 5 presents information on the unique strength and statistical significance of the associations between predictor variables and child obesity at age 11 among children with intellectual disability for the subset of

Table 5 Multivariate analyses of association between predictor variables and risk of child obesity at age eleven among children with intellectual disability $(n=484)$

\begin{tabular}{|c|c|}
\hline Variable & OR (with $95 \% \mathrm{Cl}$ )/p \\
\hline \multicolumn{2}{|l|}{ Child Ethnicity } \\
\hline White & 1 (ref) \\
\hline Mixed & $2.13(0.69-6.64)$ \\
\hline Indian & $1.02(0.13-8.29)$ \\
\hline Pakistani/Bangladeshi & $1.81(0.96-3.43)$ \\
\hline Black/Black British & $2.33(0.99-5.51)$ \\
\hline \multicolumn{2}{|l|}{ Maternal Obesity } \\
\hline No occasion & 1 (ref) \\
\hline One or two occasions & $1.50(0.86-2.62)$ \\
\hline Three to five occasions & $7.18(3.77-13.67)^{* * *}$ \\
\hline \multicolumn{2}{|l|}{ Exposure to Being Bullied } \\
\hline Age 3 & $1.51(0.37-6.20)$ \\
\hline Age 5 & $2.54(0.74-8.77)$ \\
\hline \multicolumn{2}{|l|}{ Maternal Educational Attainment } \\
\hline NVQ (L3-5) & 1 (ref) \\
\hline NVQ (L2) & $1.61(0.80-3.23)$ \\
\hline NVQ (L1 or none) & $1.15(0.58-2.28)$ \\
\hline Overseas qualifications only & $4.31(1.47-12.65)^{* *}$ \\
\hline Low fruit consumption (age 5) & $0.58(0.32-1.05)$ \\
\hline
\end{tabular}

ORs in bold indicate medium or large effect size

$O R$ odds ratio, $p$ probability

${ }^{*} p<0.05,{ }^{* *} p<0.01,{ }^{* * *} p<0.001$ 
variables that had significant bivariate associations or moderate effect sizes with obesity at age 11 among this group of children. The two strongest predictors and the only predictors that were significantly associated with child obesity in this model were persistent maternal obesity and maternal education (only having overseas qualifications). However, moderate effect sizes were also apparent for child ethnicity (mixed and Black/Black British) and being bullied at age five.

Table 6 presents information on the unique strength and statistical significance of the association between the same predictor variables and child obesity at age 11 among children without intellectual disability. The largest effect sizes in these analyses were for persistent maternal obesity and child ethnicity (Black/Black British).

Given the unexpected significance of maternal education we undertook post hoc analyses to identify the ethnic characteristics of this group and investigate whether this association was also apparent at earlier ages. The small group $(n=25)$ of mothers of children with intellectual disability who only had overseas qualifications described themselves most commonly as being of Black/ Black British (36 \%), Pakistani/Bangladeshi (32\%) and White (29\%) heritage. Higher rates of obesity in

Table 6 Multivariate analyses of association between predictor variables and risk of child obesity at age eleven among children without intellectual disability $(n=13459)$

\begin{tabular}{ll}
\hline Variable & OR (with 95\% Cl)/p \\
\hline Child ethnicity & 1 (ref) \\
White & $1.50(1.21-1.87)^{* * *}$ \\
Mixed & $1.38(1.02-1.86)^{*}$ \\
Indian & $1.43(1.18-1.74)^{* * *}$ \\
Pakistani/Bangladeshi & $1.82(1.48-2.24)^{* * *}$ \\
Black/Black British & \\
Maternal Obesity & $1($ ref $)$ \\
No occasion & $\mathbf{2 . 5 8}(\mathbf{2 . 3 0 - 2 . 9 0})^{* * *}$ \\
One or two occasions & $\mathbf{3 . 7 1}(\mathbf{3 . 2 8 - 4 . 2 0})^{* * *}$ \\
Three to five occasions & \\
Exposure to Being Bullied & $1.09(0.77-1.55)$ \\
Age 3 & $1.05(0.79-1.41)$ \\
Age 5 & \\
Maternal educational attainment & $1($ ref) \\
NVQ (L3-5) & $1.47(1.33-1.64)^{* * *}$ \\
NVQ (L2) & $1.58(1.41-1.77)^{* * *}$ \\
NVQ (L1 or none) & $1.18(0.91-1.53)$ \\
Overseas qualifications only & $1.15^{*}(1.02-1.28)$ \\
Low fruit consumption (age 5) &
\end{tabular}

ORs in bold indicate medium or large effect size $O R$ odds ratio, $p$ probability

${ }^{*} p<0.05$, ${ }^{* *} p<0.01$, ${ }^{* * *} p<0.001$ children were also apparent at age $5(15 \mathrm{v} 12 \%$, OR = 1.34 [0.99-1.83], Fisher's exact $\mathrm{p}<0.05)$ and seven $(15 \mathrm{v}$ $13 \%, \mathrm{OR}=1.23$ [0.90-1.23], Fisher's exact p n.s.), although the effect sizes were small and at age seven nonsignificant.

\section{Discussion}

Our results indicated that children with intellectual disabilities were significantly more likely than children without intellectual disabilities to be obese at ages five, seven and eleven. At ages five and seven increased risk of obesity among children with intellectual disabilities was only apparent among boys. At age eleven increased risk of obesity among children with intellectual disabilities was also apparent among girls. Among children with intellectual disability risk of obesity at ages five and seven was associated with male gender. At age eleven risk of child obesity was associated with persistent maternal obesity, maternal education (only having overseas qualifications), child ethnicity (mixed and Black/Black British) and being bullied at age five. The first two factors showed strong effect sizes and were statistically significant, the latter two, while not statistically significant, showed moderate effect sizes.

The results of the present study add to the existing literature on obesity among children with intellectual disabilities in three ways. First, it provides estimates of the risk of obesity associated with intellectual disability in a contemporary population-based sample of children with and without intellectual disability. The reported effect sizes are consistent with those reported in previous population-based samples in the UK [23], Australia [16] and the US [27].

Second, the data identify marked age effects, with obesity in children with intellectual disability rising from 15 to $17 \%$ at ages five and seven to $31 \%$ at age 11 . That nearly one in three 11 year old children with intellectual disability in the UK are obese is of considerable concern. Similar age-related trends in the increase of obesity were also evident among children without intellectual disability (12-13 \% at ages five and seven to $21 \%$ at age 11$)$. There were apparent age-related trends in the association between gender and obesity, with increased rates of obesity among boys at younger ages, but no difference at age 11. These effects may account for the noted inconsistency in the existing literature on the association between gender and risk of obesity among children with intellectual disabilities [15]. As noted in the introduction, higher rates of obesity among adults with intellectual disability have consistently been reported among women [32-34], a finding also reported in several studies of children/young people with intellectual disability $[16-18,20-22,26]$. Further research is required to identify the extent to which age moderates the association 
between gender and obesity among people with intellectual disabilities.

Finally, this is, to our knowledge, the first study to identify an association between child ethnicity, maternal migrant status and exposure to bullying and obesity among children with intellectual disability. The latter is consistent with research in the general population on the association between exposure to violence in childhood and subsequent obesity [62] and the findings of the small number of studies that have investigated the association between exposure to bullying in childhood and later obesity [63-65].

However, as in all studies, there are limitations that need to be taken into account when considering these findings. First, while having access to a large, longitudinal dataset is an asset, datasets (such as the MCS) that are designed for multiple purposes commonly utilise abbreviated forms of measures such as the abbreviated scales of cognitive functioning (rather than complete IQ tests) used in the MCS. Second, while the overall sample was relatively large, it was of insufficient size to examine the extent to which our results generalized to children with severe intellectual disability. It is important, therefore, to keep in mind, therefore, that our results regarding intellectual disability primarily relate children with mild or moderate intellectual disability.

Nevertheless, our results are consistent with previous population-based studies in indicating that children with intellectual disability, at least in high-income countries, are a high-risk group for the development of obesity accounting for $5-6 \%$ of all obese children. Interventions to reduce the prevalence and inequities in the distribution of child obesity will need to take account of the specific situation of this 'high risk' group of children.

\section{Abbreviations \\ ADHD, attention deficit hyperactivity disorder; BAS, British Ability Scales; BMI, body mass index; GCSE, General Certificate of Secondary Education; IQ, intelligence quotient; MCS, Millennium Cohort Study; NFER, National Foundation for Educational Research; NVQ, National Vocational Qualifications; OECD, Organisation for Economic Co-operation and Development; OR, odds ratio; TV, television; UCL, University College London; UK, United Kingdom}

\section{Acknowledgements}

We are grateful to The Centre for Longitudinal Studies, UCL Institute of Education for the use of MCS data and to the UK Data Archive and UK Data Service for making them available. However, they bear no responsibility for the analysis or interpretation of these data.

\section{Funding}

The research was undertaken as part of the intellectual disabilities workstream of Public Health England. However, the views expressed are those of the authors and should not be taken to necessarily represent the views of Public Health England.

\section{Availability of data and materials}

MCS data are managed by the Centre for Longitudinal Studies at the University of London (www.cls.ioe.ac.uk/) and are available to researchers registered with the Economic and Social Data Service (www.esds.ac.uk) through its data archive (www.data-archive.ac.uk).

\section{Authors' contributions}

EE conceived of the study, performed the statistical analysis and led on the drafting of the manuscript. CH, JR and SB participated in the design of the study and drafting of the manuscript. All authors read and approved the final manuscript.

\section{Competing interests}

The authors declare that they have no competing interests.

\section{Consent to publication}

Not applicable.

\section{Ethics approval and consent to participate}

Ethical approval for the MCS was granted by: the South-West Multi-Centre Research Ethics Committee (England) for MCS1 (MREC/01/6/19); the London Multi-Centre Research Ethics Committee for MCS2 (MREC/03/2/022) and MCS3 (REC Reference No. 05/MRE02/46); the Northern and Yorkshire Multi-Centre Research Ethics Committee of the NHS for MCS4 (REC Reference No. 07/MRE03/32); the Yorkshire and Humber Research Ethics Committee for MCS5 (Ref:11/YH/0203).

Received: 18 November 2015 Accepted: 14 July 2016

Published online: 27 July 2016

\section{References}

1. World Health Organization. Population-based approaches to childhood obesity prevention. Geneva: World Health Organization; 2012.

2. World Health Organization. Interim Report of the Commission on Ending Childhood Obesity. Geneva: World Health Organization; 2015.

3. Lobstein T, Baur L, Uauy R. Obesity in children and young people: A crisis in public health. Obes Rev. 2004;5:54-104.

4. Public Health England. From evidence into action: opportunities to protect and improve the nation's health. London: Public Health England; 2014.

5. England NHS. Five Year Forward View. London: NHS England; 2014.

6. Healthy People 2020: Nutrition and Weight Status [http://www. healthypeople.gov/2020/topics-objectives/topic/nutrition-and-weight-status]. Accessed 19 July 2016

7. Australian Government Preventative Health Task Force. Australia: The Healthiest Country by 2020. Technical Report 1: Obesity in Australia: a need for urgent action. Canberra: Australian Government; 2020.

8. World Health Organization. Rio Political Declaration on Social Determinants of Health. Geneva: World Health Organization; 2011. http://www.who.int/ sdhconference/declaration/en/

9. World Health Organization. ICD-10 Guide for Mental Retardation. Geneva: World Health Organization; 1996.

10. Maulik PK, Mascarenhas MN, Mathers CD, Dua T, Saxena S. Prevalence of intellectual disability: A meta-analysis of population-based studies. Res Dev Disabil. 2011:32:419-36.

11. Hatton C, Emerson E, Glover G, Robertson J, Baines S, Christie A. People with Learning Disabilities in England 2013. London: Public Health England; 2014

12. Ells L, Lang R, Shield J, Wilkinson J, Lidstone J, Coulton S, Summerbell C. Obesity and disability - a short review. Obes Rev. 2006;7:341-5.

13. McGillivray J, McVilly K, Skouteris H, Boganin C. Parental Factors Associated With Obesity In Children With Disability: A Systematic Review. Obes Rev. 2013:14(7):541-54

14. Public Health England. Obesity and Disability: Children and Young People. London: Public Health England; 2014.

15. Maiano C. Prevalence and risk factors of overweight and obesity among children and adolescents with intellectual disabilities. Obes Rev. 2011:12: 189-97.

16. Emerson E, Robertson J. Obesity in young Australian children with intellectual disabilities or borderline intellectual functioning. Int J Pediatr Obes. 2010;5:320-6.

17. De S, Small J, Baur L. Overweight and obesity among children with developmental disabilities. J Intellect Dev Disabil. 2008;33:43-7.

18. Begarie J, Maiano C, Leconte P, Ninot G. The prevalence and determinants of overweight and obesity among French youths and adults with intellectual disabilities attending special education schools. Res Dev Disabil. 2013;34:1417-25.

19. Salaun L, Berthouze-Aranda SE. Obesity in school children with intellectual disabilitiesc in France. J Appl Res Intellect Disabil. 2011;24:333-40. 
20. Takeuchi E. Incidence of obesity among school children with mental retardation in Japan. Am J Mental Retard. 1994;99:283-8.

21. Choi E, Park H, Ha Y, Hwang WJ. Prevalence of Overweight and Obesity in Children With Intellectual Disabilities in Korea. J Appl Res Intellect Disabil. 2012;25:476-83

22. Lin J, Yen C, Li C, Wu J. Patterns of obesity among children and adolescents with intellectual disabilities in Taiwan. J Appl Res Intellect Disabil. 2005;18: 123-9.

23. Emerson E. Overweight and obesity in 3 and 5 year old children with and without developmental delay. Public Health. 2009;123:130-3.

24. Slevin E, Truesdale-Kennedy M, McConkey R, Livingstone B, Fleming P. Obesity and overweight in intellectual and non-intellectually disabled children. J Intellect Disabilit Res. 2014;58:211-20.

25. Stewart L, Van de Ven L, Katsarou V, Rentziou E, Doran M, Jackson P, Reilly $\mathrm{J}$, Wilson D. High prevalence of obesity in ambulatory children andadolescents with intellectual disability. J Intellect Disabilit Res. 2009;53: 882-6.

26. Foley JT, Lloyd M, Temple VA. Obesity trends of 8-18 year old Special Olympians: 2005-2010. Res Dev Disabil. 2014;35:705-10.

27. Bandini L, Danielson M, Esposito LE, Foley JT, Fox MH, Frey GC, Fleming RK, Krahn G, Must A, Porretta DL, et al. Obesity in children with developmenta and/or physical disabilities. Disability Health J. 2015;8:309-16.

28. Fox RA, Hartney CW, Rotatori AF, Kurpiers EM. Incidence of obesity among retarded children. Educ Training Mental Retard. 1985;20:175-81.

29. Frey GC, Chow B. Relationship between BMI, physical fitness, and motor skills in youth with mild intellectual disabilities. Int J Obes (Lond). 2006;30: 861-7.

30. Lloyd M, Foley JT, Temple VA. Body mass index of children and youth with an intellectual disability by country economic status. Prev Med. 2014;69: 197-201.

31. Lloyd M, Temple VA, Foley JT. International BMI comparison of children and youth with intellectual disabilities participating in Special Olympics. Res Dev Disabil. 2012;33:1708-14.

32. Bhaumik S, Watson JM, Thorp CF, Tyrer F, McGrother CW. Body mass index in adults with intellectual disability: Distribution, associations and service implications: A population-based prevalence study. J Intellect Disabil Res. 2008:52:287-98

33. Melville C, Hamilton S, Hankey C, Miller S, Boyle S. The prevalence and determinants of obesity in adults with intellectual disabilities. Obes Rev. 2007;8:223-30.

34. Melville CA, Cooper SA, Morrison J, Allan L, Smiley E, Williamson A. The prevalence and determinants of obesity in adults with intellectual disabilities. J Appl Res Intellect Disabil. 2008;21:425-37.

35. Li H, Frey GC, McCormick BP, Johnston JD. Comparison of obesity among Chinese and U.S. Special Olympic athletes with intellectual disabilities. Res Dev Disabil. 2015:41/42:94-100

36. Plewis I. Millennium Cohort Study: First Survey. Technical Report on Sampling. 2nd ed. London: Centre for Longitudinal Studies, Institute of Education, University of London; 2003.

37. Plewis I, Ketende S. Millennium Cohort Study: Technical Report on Response. London: Centre for Longitudinal Studies, Institute of Education, University of London; 2006.

38. Hansen K, editor. Millennium Cohort Study: A Guide to the Datasets. Eighth Edition. First, Second, Third, Fourth and Fifth Surveys. London: Centre for Longitudinal Studies, Institute of Education, University of London; 2014.

39. Gallop K, Rose N, Wallace E, Williams R, Cleary A, Thompson A, Burston K, Frere-Smith T, Dangerfield P, Tietz S. Millennium Cohort Study Fifth Sweep (MCS5): Technical Report. London: Ipsos Mori; 2013.

40. Platt L. Millennium Cohort Study: Initial findings from the Age 11 survey. London: Centre for Longitudinal Studies, Istitute of Education, University of London; 2014

41. Johnson J. Millennium Cohort Study: Geographic Identifiers in MCS. London: Centre for Longitudinal Studies, Institute of Education, University of London; 2009.

42. Johnson J. Millennium Cohort Study: Psychological, Developmental and Health Inventories. London: Centre for Longitudinal Studies, Institute of Education, University of London; 2012.

43. Plewis I. The Millennium Cohort Study: Technical Report on Sampling. 4th ed. London: Centre for Longitudinal Studies; 2007.

44. Bracken BA. Bracken School Readiness Assessment. London: Harcourt Assessment; 2002
45. Elliott C, Smith P, McCulloch K. British Ability Scales. 2nd ed. London: nferNelson; 1997.

46. Hansen K, editor. Millennium Cohort Study: First, Second, Third and Fourth Surveys. A Guide to the Datasets. 7th ed. London: Centre for Longitudinal Studies, Institute of Education, University of London; 2012.

47. Jones EM, Schoon I. Child cognition and behaviour. In: Hansen K, Joshi H, editors. Millennium Cohort Study Third Survey: A user's guide to initial findings. London: Centre for Longitudinal Studies, Institute of Education, University of London; 2008. p. 118-44.

48. Cole TJ, Bellizzi MC, Flegal KM, Dietz WH. Establishing a standard definition for child overweight and obesity worldwide: international survey. Br Med J. 2000;320:1240-5

49. Hawkins S, Cole T, Law C. An ecological systems approach to examining risk factors for early childhood overweight: findings from the UK Millennium Cohort Study. J Epidemiol Community Health. 2009;63:147-55.

50. Brophy S, Cooksey R, Gravenor M, Mistry R, Thomas N, Lyons R, Williams R. Risk factors for childhood obesity at age 5: Analysis of the Millennium Cohort Study. BMC Public Health. 2009;9:467.

51. Reilly J. Assessment of Childhood Obesity: National Reference Data or International Approach? Obes Res. 2002;10:838-40.

52. Connelly R. Drivers of Unhealthy Weight in Childhood: Analysis of the Millennium Cohort Study: Scottish Government Social Research Report. Scottish Government: Edinburgh; 2011.

53. Pan H, Cole TJ. LMSgrowth, a Microsoft Excel add-in to access growth references based on the LMS method. Version 2.77. http://www. healthforallchildren.co.uk/. 2012. Accessed 19 July 2016.

54. Wright C, Booth I, Buckler J, Cameron N, Cole T, Healy M, Hulse JA, Preece MA, Reilly JJ, Williams AF. Growth reference charts for use in the United Kingdom. Arch Dis Child. 2002;86:11-4.

55. Dinsdale H, Ridler C, Ells $L$. A simple guide to classifying body mass index in children. Oxford: National Obesity Observatory; 2011.

56. Barlow SE, Dietz WH. Obesity evaluation and treatment: expert committee recommendations. Pediatrics. 1998:102:e29.

57. Goodman R. Psychometric properties of the Strengths and Difficulties Questionnaire (SDQ). J Am Acad Child Adolesc Psychiatry. 2001;40:1337-45.

58. Office for National Statistics. Family Spending. Swansea: Office for National Statistics: 2014

59. Pantazis C, Gordon D, Levitas R. Poverty and Social Exclusion in Britain: The Millennium Survey. Bristol: Policy Press; 2006.

60. Noble M, McLennan D, Wilkinson K, Whitworth A, Barnes H, Dibben C, McLennan D, Wilkinson K, Whitworth A, Barnes H, Dibben C. The English Indices of Deprivation 2007. London: Communities and Local Government; 2008

61. Olivier J, Bell ML. Effect Sizes for 2x2 Contingency Tables. PLoS One. 2013;8:e58777

62. Gooding HC, Milliren C, Austin SB, Sheridan MA, McLaughlin KA Exposure to violence in childhood is associated with higherbody mass index in adolescence. Child Abuse Negl. 2015:50:151-8.

63. Stensland SO, Thoresen S, Wentzel-Larsen T, Dyb G. Interpersonal violence and overweight in adolescents: The HUNT Study. Scand J Public Health. 2015:43:18-26

64. Mamun AA, O'Callaghan MJ, Williams GM, Najman JM. Adolescents bullying and young adults body mass index and obesity: a longitudinal study. Int J Obes (Lond). 2013:37:1140-6.

65. Adams REBW. Peer victimization as a predictor of depression and body mass index in obese and non-obese adolescents. J Child Psychol Psychiatry. 2008;49:858-66. 